\title{
Enxerto de submucosa porcina no tratamento de lesões duodenais em cães ${ }^{1}$
}

\author{
Porcine submucosa graft for the treatment of duodenal injuries in dogs
}

\begin{abstract}
Zacarias Alves de Souza Filho², Fernando Hintz Greca ${ }^{3}$, Sergio Luiz Rocha ${ }^{4}$, Sergio Ossamu Ioshii ${ }^{5}$, Ana Carolina Domanski ${ }^{6}$, Diogo Kfouri ${ }^{6}$, Priscila Dall Prá Campos ${ }^{6}$, Ruy Fernando Kuenzer Caetano da Silva ${ }^{6}$

1. Disciplina de Técnica Operatória e Cirurgia Experimental da Pontifícia Universidade Católica do Paraná.

2. Professor Titular de Clínica Cirúrgica, Disciplina de Técnica Operatória e Cirurgia Experimental e do Programa de Pós-Graduação em Clínica Cirúrgica da Pontifícia Universidade Católica do Paraná.

3. Professor Titular e Coordenador da Disciplina de Técnica Operatória e Cirurgia Experimental e do Programa de Pós-Graduação em Clínica Cirúrgica da Pontifícia Universidade Católica do Paraná e Prof. Adjunto da Disciplina de Cirurgia Geral da UFPR.

4. Prof. Adjunto da Disciplina de Anatomia Médica da PUCPR e UFPR. Prof. Adjunto da Disciplina de Técnica Operatória e Cirurgia Experimental da PUCPR e do Programa de Pós-Graduação em Clínica Cirúrgica. Doutor em Clínica Cirúrgica pela UFPR.

5. Professor da Disciplina de Patologia Experimental da Pontifícia e do Programa de Pós-Graduação em Clínica Cirúrgica da Universidade Católica do Paraná.

6. Acadêmicos do curso de Medicina da Disciplina de Técnica Operatória e Cirurgia Experimental da Pontifícia Universidade Católica do Paraná.
\end{abstract}

\section{RESUMO}

Objetivo: Avaliar a biocompatibilidade e a eficiência da SID (submucosa de intestino delgado) porcina, quando usada como enxerto para reparar lesões duodenais. Métodos: O estudo experimental foi realizado em oito cães. Um segmento da parede da segunda porção do duodeno foi ressecada e a lesão foi reparada com um enxerto de submucosa de intestino delgado porcina. No $120^{\circ}$ dia de pós-operatório os animais foram submetidos a eutanásia e o segmento do duodeno com o enxerto foi retirado para avaliações macroscópica e microscópica. Resultados: Não houve infecção, deiscência da sutura ou fístula. O estudo microscópico revelou completa re-epitelização em 75\% dos casos, com proliferação fibroblástica moderada em 87,5\% dos casos. Conclusão: A SID porcina é um enxerto eficaz para reparo de lesões com perda de substância em duodeno de cães.

Descritores: Transplantes. Lesões. Duodeno. Experimentação animal. Cães.

\begin{abstract}
Purpose: To evaluate the biocompatibility and effectiveness of porcine SIS (small intestinal submucosa), when used as a patch to repair a defect on the anterior duodenal wall. Methods: The experimental study was performed in 8 dogs. A segment of the anterior duodenal wall was removed and the defect was repaired with a patch of porcine intestinal submucosa. On the $120^{\text {th }}$ post operative day the animals were sacrified and the segment of duodenum containing the patch was removed to a macroscopic and microscopic evaluation. Results: There was no infection, suture dehiscence or fistula. The microscopic evaluation showed complete re-epithelization in $75 \%$ of the cases, with moderate fibroblastic proliferation in 87, 5\% of the cases. Conclusion: The porcine SIS used as a patch acts as a tissue substitute for repairing induced lesions in duodenal wall of dogs.Pesquisar a eficácia da submucosa de intestino delgado
\end{abstract}

Key words: Transplants. Injuries. Duodenum. Animal experimentation. Dogs.

\section{Introdução}

O duodeno é a porção do sistema digestório cujo nome deriva da palavra latina duodeni, a qual traduz sua extensão de aproximadamente doze polegadas. Estende-se do piloro à flexura duodenojejunal, dividindo-se em quatro porções: superior ou primeira; descendente ou segunda; inferior ou terceira e ascendente ou quarta ${ }^{1}$. Diferentemente do restante do intestino delgado, o duodeno, no homem, é fixo aos planos profundos, apresentando íntima conexão com o pâncreas e com os ductos secretórios biliares e pancreáticos que nele desembocam ${ }^{2}$.
Em sua porção caudal, a face posterior não apresenta revestimento peritoneal, sendo este um dos fatores que maior vulnerabilidade confere ao órgão. Há também, outros fatores adversos à cicatrização e que favorecem a ocorrência de deiscência de suturas e a formação de fístulas: a) pouca mobilidade, por fixação ao pâncreas e aos ductos acima referidos; b) implantação em sua segunda porção dos ductos biliar e pancreático, que além de comprometer a mobilidade, lançam em sua luz um grande volume de secreções ricas em enzimas digestivas; c) relativa fragilidade de suas paredes que não suportam com solidez as suturas ${ }^{3}$. As graves complicações que freqüentemente envolvem os 
procedimentos cirúrgicos sobre o duodeno, assim como as lesões traumáticas neste segmento do sistema digestório, constituem preocupação constante aos serviços de cirurgia, pelos elevados índices de mortalidade que apresentam. A deiscência da sutura de coto duodenal é uma das mais graves complicações que podem ocorrer após ressecções gástricas a Billroth II. Esta complicação ocorre em 3 a 5\% destes procedimentos. Fístulas bílio-digestivas envolvendo o duodeno, também são uma complicação cirúrgica freqüente ${ }^{4}$. As lesões traumáticas duodenais podem determinar um grande número de procedimentos, desde os mais simples como a sutura primária da lesão até os mais complexos, tendo como exemplo a exclusão pilórica, a diverticulização duodenal e a duodenopancreatectomia ${ }^{5}$. A submucosa de intestino delgado (SID) de suínos é uma matriz colágena extracelular que vem sendo utilizada com bons resultados no reparo de tecidos vasculares ${ }^{6}$, do sistema urinário $^{7}$ e bexiga $^{8}$, do intestino delgado ${ }^{9}$, da parede abdominal ${ }^{10}$, cartilagens ${ }^{11}$,tendões ${ }^{12}$ entre outros. Segundo diversos autores, a SID apresenta características próprias que proporcionam a ela vantagens em relação aos demais enxertos biológicos. Dentre eles estão os glicosaminoglicanos que conferem bioatividade a diversas citocinas e fatores de crescimento que atuam na revascularização e cicatrização de ferimentos ${ }^{13}$. O fator de crescimento do endotélio (VEGF) induz a formação de estruturas similares a capilares fenestrados na matriz de fibrina, promovendo uma neovascularização local ${ }^{14}$. O PDGF (fator de crescimento derivado de plaquetas) atua na proliferação fibroblástica ${ }^{15,16}$ e é suplementado pela imediata deposição de fibronectina, responsável primária pelo recrutamento e pela retenção de células do hospedeiro que povoarão o local da ferida ${ }^{17}$. Com relação à resposta imune de SID, observou-se que esta está restrita aos linfócitos Thelper 2, que ativam interleucinas, as quais produzem anticorpos não ligados ao complemento e, conseqüentemente, não há uma rejeição típica do tecido implantado ${ }^{18,19}$. A resistência à infecção está provavelmente relacionada ao rico e rápido desenvolvimento de suprimento sangüíneo $^{20}$. A SID já foi utilizada como reparo de lesões duodenais em porcos, combinada com enxerto de elastina, revelando-se eficaz para o reparo das lesões ${ }^{21}$. As promissoras características da SID, os bons resultados descritos na literatura em relação à sua aplicação, a morbidade das lesões duodenais e a ausência de um consenso em relação ao seu tratamento nos motivaram a pesquisar experimentalmente a eficácia da SID porcina como enxerto para correção de lesões duodenais com perda de substância em cães.

\section{Métodos}

Este estudo obedeceu às normas de pesquisa com animais preconizadas pelo Colégio Brasileiro de Experimentação Animal (COBEA), instituição filiada ao International Council for Laboratory Animal Science. Utilizaram-se oito cães mestiços, de ambos os sexos, com peso entre 10 e $20 \mathrm{~kg}$, obtidos no Biotério Central da PUCPR. Os animais foram mantidos em ambiente adequado, com temperatura e luminosidade naturais. Utilizou-se na indução anestésica o Tiopental sódico a 2,5\%, administrado por via endovenosa na dose de $10 \mathrm{mg} / \mathrm{kg}$. Todos os animais foram submetidos à entubação orotraqueal. A manutenção anestésica foi realizada com citrato de fentanila $(0,05 \mathrm{mg} /$ $\mathrm{kg})$ e misolan $(0,2 \mathrm{mg} / \mathrm{kg})$ por via endovenosa; todo o experimento foi realizado no Laboratório de Técnica Operatória e Cirurgia Experimental da PUCPR. Sob condições assépticas, os animais foram submetidos à laparotomia mediana supra e infra-umbilical. A porção duodenal foi exposta e ressecou-se, em sua segunda porção, todas as camadas até atingir-se a luz do órgão, em segmento elíptico de aproximadamente $3 x 1 \mathrm{~cm}$.(Figura 1 ).

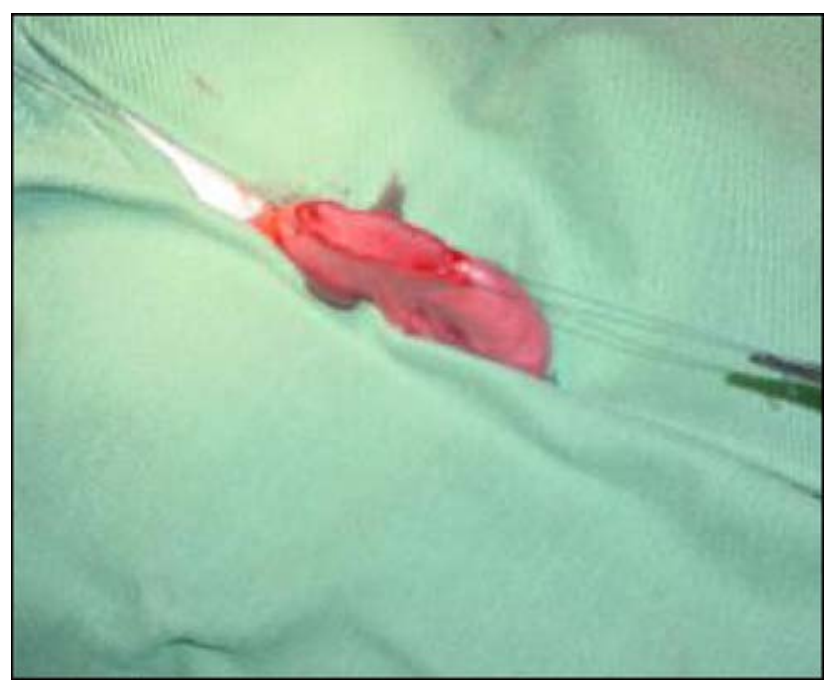

FIGURA 1 - Ressecção de segmento elíptico de parede duodenal

Após obtenção da camada de submucosa de intestino delgado, como será descrito posteriormente, foi realizado o reparo do defeito criado na parede intestinal com o implante de um segmento de SID, em forma retangular medindo $3 \mathrm{x} 4$ cm (Figura 3), fixados através da sutura de seus dois folhetos, que substituíram o segmento retirado. Este foi suturado de forma contínua às camadas serosa e muscular do duodeno com fio Monocryl ${ }^{\circledR}$ 3.0.(Figura 2).

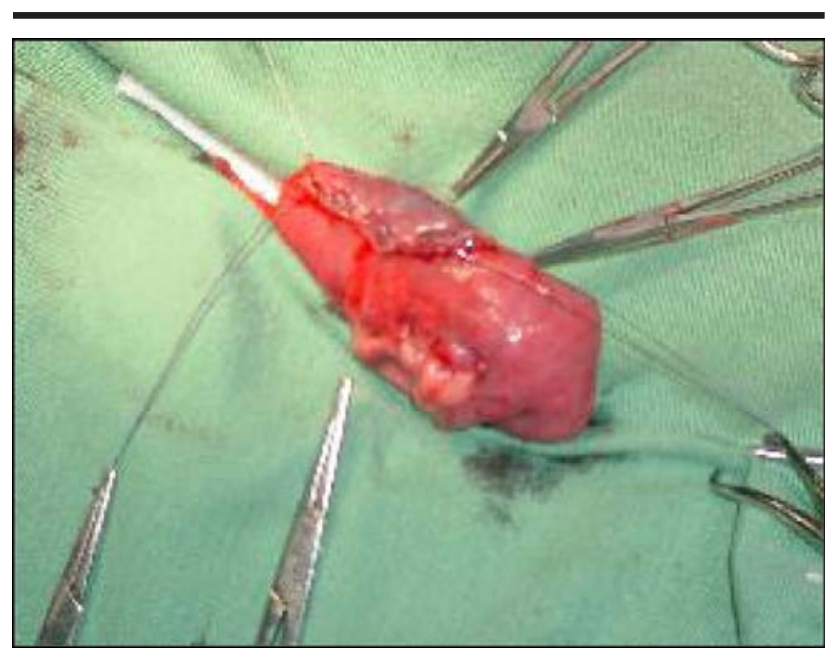

FIGURA 2 - Submucosa de intestino delgado substituindo parede duodenal 


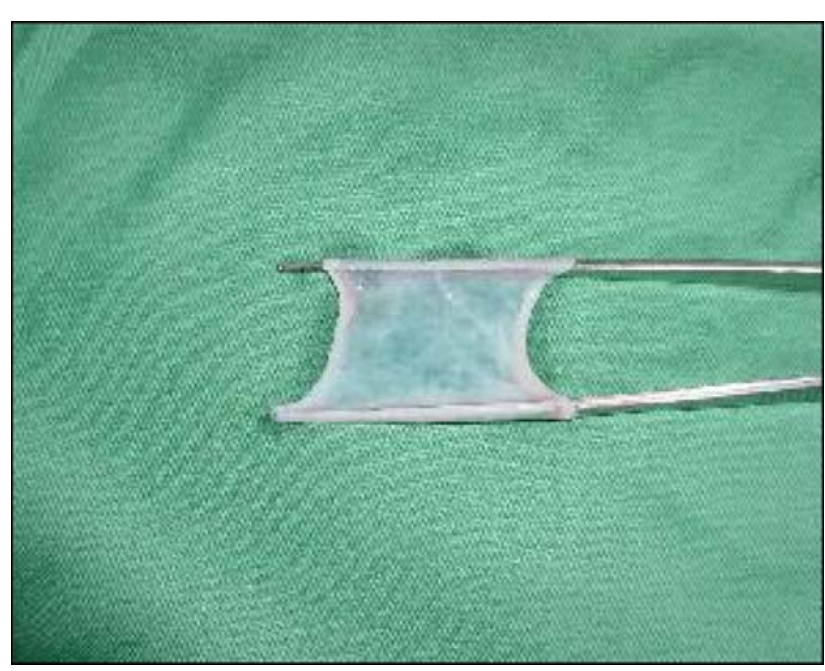

FIGURA 3 - Submucosa de intestino delgado

O peritônio foi suturado de forma contínua com Categute ${ }^{\circledR}$ 3.0, a aponeurose com fio de algodão $2.0 \mathrm{em}$ sutura interrompida, e a pele, com Mononylon ${ }^{\circledR} 3.0$, pontos Donatti. Iniciou-se alimentação com 24 horas de pósoperatório com uma dieta pastosa. Este alimento foi instituído durante 5 dias, quando então os cães passaram a ser alimentados com ração tradicional canina ad libitum. Não foi administrada antibioticoterapia. Não houve mortalidade.No $120 .^{\circ}$ pós-operatório, os cães foram submetidos novamente a laparotomia através da cicatriz da primeira operação. A cavidade foi rigorosamente inspecionada, no sentido de verificar-se a presença de deiscências, abscessos, fístulas e estenoses. As porções duodenais que continham o implante foram ressecadas em bloco. Ao final, realizou-se a eutanásia dos cães com dose letal de cloreto de potássio, administrado por via endovenosa, com o animal ainda anestesiado. Segmentos de todas as peças foram fixados em formalina a $10 \%$ e encaminhadas para estudo histopatológico. Após inclusão em parafina, as peças forma submetidas a cortes de 5 micrômetros, que por sua vez foram corados pela hematoxilina-eosina, para avaliar: regeneração epitelial, fibrose, inflamação e incorporação do enxerto e sirius red para análise da densitometria do colágeno. O processo cicatricial baseou-se nos seguintes parâmetros: fibrose , reepitelização, inflamção aguda traduzindo diretamente o exsudato neutrofílico, e a inflamação crônica relatando o infiltrado linfo-neutrofílico. Esses parâmetros foram graduados em: grau 0, ausente; grau 1, presença discreta; grau 2, presença moderada; grau 3, intensa. Analisando-se os cortes histológicos corados com sirius red em microscópio óptico da marca OlympusÒ com aumento de 200 x, com fonte de luz polarizada. As fibras de colágeno tipo I ou maduro foram identificadas por sua coloração vermelho-alaranjada e as fibras de colágeno III ou imaturo por sua coloração esverdeada ${ }^{22}$. As imagens foram captadas por uma câmera Sony, CCD 101, transmitidas a um microcomputador PentiumÒ, e sua análise foi realizada através do aplicativo Optimas, 6.2. Este programa possibilitou a determinação de colágeno tipo I, colágeno tipo III e colágeno total. Para obtenção da submucosa de intestino delgado, foi mobilizado um segmento de jejuno situado a $20 \mathrm{~cm}$ da flexura duodeno-jejunal, sendo então realizada enterectomia de $10 \mathrm{~cm}$ a partir desse ponto. Após a obtenção do segmento de jejuno, seu mesentério foi removido. O segmento intestinal foi então invertido de modo que a mucosa ficasse voltada para fora. Esta foi removida através de raspagem com bisturi, sendo a lâmina posicionada em sentido transversal am maior eixo do intestino. Foi desfeita a inversão do segmento pela mesma técnica, irrigase abundantemente com solução salina isotônica. $O$ folheto de submucosa obtido foi, então, conservado em solução de sulfato de neomicina $10 \%$.

\section{Resultados}

Não houve infecção, fístula ou estenose. A macroscopia demonstrou o local do enxerto já cicatrizado, com cobertura completa da camada mucosa. (Figura 4).

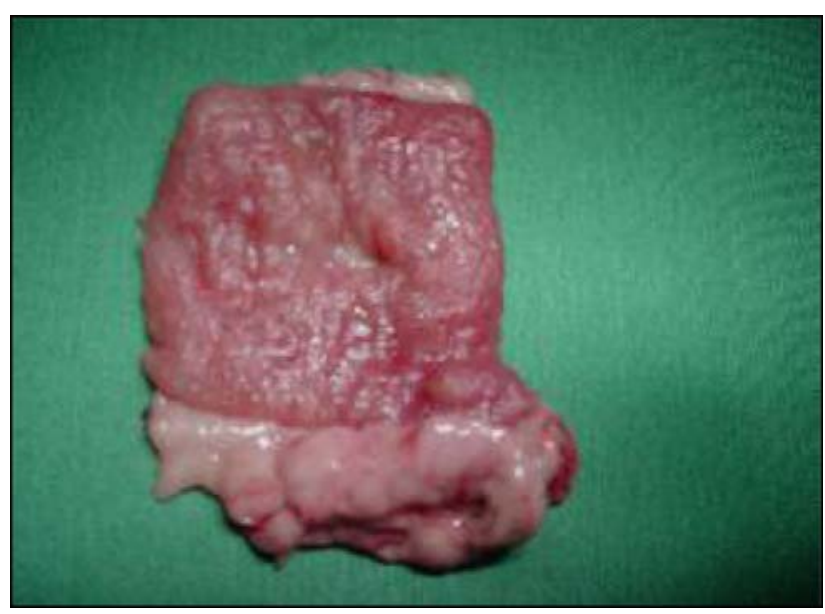

FIGURA 4 - Macroscopia - Aspecto interno de enxerto de (SID) em duodeno

Externamente não foi possível identificar cicatriz na camada muscular. O estudo anátomo-patológico pela coloração hematoxilina-eosina revelou re-epitelização completa em $75 \%$ dos casos. A proliferação fibroblástica (fibrose) foi moderada em $87,5 \%$ dos cães e intensa em $12,5 \%$. A resposta inflamatória aguda, avaliada através da presença de exsudato neutrofílico foi ausente na maioria dos cães (75\%). Em 25\% foi discreta. A presença de infiltrado inflamatório linfo-plasmocitário foi discreta em $62,5 \%$ dos casos e moderada em 37,5\%. (Tabelas 1 e 2).

A quantificação do colágeno pela coloração sirus-red demonstrou haver maior porcentagem de colágeno maduro (tipo I) em relação ao imaturo (tipo III) em 100\% dos cães. A quantidade de colágeno maduro variou entre 75,89\% e $92,10 \%$, com média de 83,96\%. A de colágeno imaturo oscilou entre 7,09\% e 24,11\% (média 16,04\%). (Tabela 3). 
TABELA 1 - Estudo anátomo-patológico. (microscopia) - Coloração HE

\begin{tabular}{ccccc}
\hline Animal & Fibrose & Reepitelização & InflamaçãoAguda & Inflamação Crônica \\
\hline Cão 1 & 2 & 3 & 0 & 1 \\
Cão 2 & 2 & 3 & 0 & 1 \\
Cão 3 & 3 & 2 & 1 & 2 \\
Cão 4 & 2 & 3 & 0 & 1 \\
Cão 5 & 2 & 2 & 1 & 2 \\
Cão 6 & 2 & 3 & 0 & 2 \\
Cão 7 & 2 & 3 & 0 & 1 \\
Cão 8 & 2 & 3 & 0 & 1 \\
\hline
\end{tabular}

Grau 0 = ausente; Grau1 = discreta; Grau 2 = moderada; Grau 3 = intensa/completa.

TABELA 2 - Variáveis histopatológicas; percentual dos valores analisados

\begin{tabular}{lllll}
\hline Classificação & Fibrose & Reepitelização & InflamaçãoAguda & Inflamação Crônica \\
\hline Ausente & $0(0 \%)$ & $0(0 \%)$ & $6(75 \%)$ & $0(0 \%)$ \\
Discreta & $0(0 \%)$ & $0(0 \%)$ & $2(25 \%)$ & $5(62,5 \%)$ \\
Moderada & $7(87,5 \%)$ & $2(25 \%)$ & $0(0 \%)$ & $3(37,5 \%)$ \\
Intensa & $1(12,5 \%)$ & $6(75 \%)$ & $0(0 \%)$ & $0(0 \%)$ \\
\hline
\end{tabular}

TABELA 3 - Estudo anátomo-patológico (microscopia) Coloração sirus-red

\begin{tabular}{lll}
\hline Animal & $\begin{array}{c}\text { Colágeno } \\
\text { Imaturo }\end{array}$ & $\begin{array}{c}\text { Colágeno } \\
\text { Maduro }\end{array}$ \\
\hline Cão 1 & $11,63 \%$ & $88,37 \%$ \\
Cão 2 & $7,90 \%$ & $92,10 \%$ \\
Cão 3 & $8,16 \%$ & $91,84 \%$ \\
Cão 4 & $16,26 \%$ & $83,74 \%$ \\
Cão 5 & $15,79 \%$ & $84,21 \%$ \\
Cão 6 & $8,76 \%$ & $91,24 \%$ \\
Cão 7 & $24,11 \%$ & $75,89 \%$ \\
Cão 8 & $22,63 \%$ & $77,37 \%$ \\
\hline MÉDIA & $16,04 \%$ & $83,96 \%$ \\
\hline
\end{tabular}

\section{Discussão}

Grandes lesões duodenais com significativa perda tecidual são sempre preocupantes e de difícil tratamento ${ }^{23}$. Requerem técnicas inovadoras e apresentam elevada morbidade. Em se tratando de vítimas de feridas traumáticas, as quais normalmente apresentam lesões associadas de grandes vasos abdominais e outras vísceras, a escolha da melhor forma de reparo para o duodeno pode tornar-se difícil ${ }^{24}$. As chances de sobrevida e boa qualidade de vida são maiores quando o reparo da lesão é realizado de maneira simples, concreta e definitiva; em um menor espaço de tempo. A maioria das lesões duodenais pode ser reparada por sutura primária em um ou dois planos, com ou sem a interposição de um remendo seroso ${ }^{4}$. Já as lesões graves, apresentam elevado grau de deiscência e para seu tratamento devem ser utilizadas técnicas mais complexas, como a exclusão pilórica ou a estomização, que poderão acarretar em posteriores procedimentos de reconstrução mais extensos ${ }^{5}$. Bons resultados foram obtidos, experimentalmente, com diferentes tipos de enxerto para correção de lacerações duodenais, como a própria membrana submucosa ${ }^{21}$, o PTFE (politetrafluoretileno) ${ }^{25}$ e a serosa jejunal ${ }^{26}$. O enxerto que empregamos no reparo das lesões duodenais pode ser obtido de maneira fácil e rápida, com baixo custo. A SID proporciona uma barreira no sítio da lesão, enquanto rapidamente pela matriz colágena, o tecido local cresce e se regenera tomando o seu lugar ${ }^{16,17}$. O estudo histológico por HE evidenciou proliferação fibroblástica moderada em $87,5 \%$ dos casos. Isso demonstra boa cicatrização no local do enxerto em relação ao tempo decorrido após a operação (120 dias). Houve re-epitelização completa da mucosa em 75\% dos casos, no entanto, não foi possível avaliar com precisão a regeneração da camada muscular ${ }^{20}$. A incorporação do enxerto foi completa em $100 \%$ dos animais e a resposta inflamatória variou, de ausente a discreta, na maioria dos casos. Os resultados verificados na coloração sirus-red vieram a confirmar a satisfatória resposta cicatricial apresentada pelo enxerto. Com 120 dias de pós-operatório, a porcentagem de colágeno maduro foi de 83,96\%, valor compatível com uma boa cicatrização. Com características de não haver rejeição ou infecção, a matriz colágena extracelular se encaixa como uma base propícia para uma regeneração tecidual ideal, com baixíssimo grau de retração tecidual, sem estenose e sem o aparecimento de fístulas. $\mathrm{O}$ tempo cirúrgico utilizado para o reparo propriamente dito foi aproximadamente de 20 minutos .

\section{Conclusão}

O presente experimento demonstrou ser a submucosa de intestino delgado porcina um enxerto eficaz para reparo de lesões com perda de substância em segunda porção de duodeno de cães.

\section{Referências}

1. Gardener E, Gray D, Orahhily. Anatomia. Rio de Janeiro: Guanabara Koogan; 1988. 
2. Pires PWA. Duodeno. In: Pires PWA. Anatomia Cirúrgica. Rio de Janeiro: Guanabara Koogan; 1999. p.455-8.

3. Gomes CG, Vinhaes JC. Complicações após operações gástricas. In: Vinhaés JC. Clínica e terapêutica cirúrgicas. Rio de Janeiro: Guanabara Koogan; 1999. p.583-96.

4. Boffard K, Degiannis E. Duodenal Injuries. Br J Surg. 2000; 87: 1473-79.

5. Teixeira WB, Onofre AF. Trauma do Duodeno. In: Freire E. 1.ed. Trauma a doença dos séculos. São Paulo: Atheneu; 2001. p.1559-68.

6. Roeder R, Wolf J, Lianakis N. Compliance, elastic modulus, and burst pressure of small intestinal submucos, small diameter vascular grafts. J. Biomed Mater. 1999; 47: 65.

7. Vaught JD, Kroop BP, Sawyer BD, Rippy MK. Detrusor regeneration in the rat using porcine small intestine submucosal grafts. Funcional inervation and receptor espression. J. Urol. 1996; 155 (1): 374-78.

8. Greca FH, Santos EAA, Gonçalves PCZ, Chin EWK, Ioshii SO. Retalho de submucosa de intestino Delgado autólogo para aumento da capacidade da bexiga: estudo experimental em cães. Rev Col Bras Cir. 2002; 29 (5): 294-99.

9. Greca FH, Biondo-Simões MLP, Ioshii SO, Chin EWK, Kimura LY, el Tawil II, Berlatto F. Enxerto de submucosa intestinal para reparo de parede de intestino delgado de cães. Acta Cir Bras. 2001;16 Supl 2:16-21.

10. Prevel SAF, Eppley B, Summerlin DJ, Jackson JR, Mccarty M, Badylak SF. Small intestinal submucosa: utilization for repair of rodent abdominal wall defects. Tissue Eng. 1996; 2: 209-17.

11. Peel SAF, Chen H, Renlund R, Kandel RA. Formation of a SIS cartilage composite graft in vitro and its use in repair of articular cartilage defects. Tissue Eng. 1998; 4(2): 143-55.

12. Greca FH, Dalaremo VC, Silva APG, Mima WH, Okawa L, Alencar TG, Ramos EJB. Evaluation of porcine small intestine submucosa in Achiles Tendon repair. J Am Coll Surg. 2003; 197 (3):45.

13. Hodde JP, Mcpherson TB, Savaiano JK, Badylak SF. Vascular endotelial growth factor in SIS. SIS Simp. 1998; 93.

14. Hodde JP, Badylak SF, Brightman AO, Voyti Harbin SL. Glycosaminoglycan content of small intestine submucosa: a bioscaffold for tissue replacement. Tissue Eng. 1996; 2: 209-17.

15. Voytik SL, Brightman AO, Kraine M, Badylak SF. Identification of extractable growth factors from small intestinal submucosa. J Cel Biol. 1997; 67: 478-501.

16. Liang HA. Determination of patelet derived growth factor in small intestinal submucosa. SIS Simp. 1998; 93.

17. Mcpherson TB, Badylak F. Characterization of fibronectin derived from porcine small intestinal submucosa. Tissue Eng. 1998; 4: 75-83.

18. Metzger DW, Mcpherson TB, Badylak SF. Immune responses to xenogenic Sis implants. SIS Simp.1998; 33.

19. Allman AJ, Mcpherson TB, Merril LA, Moyad TF, Badylak SF. Xenogenic extracellular matrix grafts elicit a th -2 restricted immune response. Transplantation. 2001; 71 (11): 1631-40.

20. Badylak SF, Coffei AC, Lantz GC. Comparison of resistance to infection of small intestinal submucosa arterial autografts versus PTFE arterial prostheses in a dog model. J Vasc Surg. 1994; 19:465.

21. Kajitani M; Wadia, Xie H, Hinds MT, Shalaby SW, Swartz $\mathrm{KR}$, Gregory KW. Use of a new elastin patch and glue for repair of a major duodenal injury. Asaio J. 2000; 46 (4): 409-14.

22. Junqueira LCU, Cossermelli W, Brentani RR. Differencial stain of collagen type I, II or III by sirius red and diaphragmatic defects. Ann Surg. 1981; 193(5): 606-9.

23. Ivatury RR, Gaudino J, Nallathambi M, Ramirez SG, Stahl WM. Treatment of penetrating duodenal injuries: primary repair vs. repair with decompressive enterostomy serosal patch. J Trauma. 1985; 25 (4): 337-41.

24. Velmahos G, Kamel E. Complex repair for the management of duodenal injuries. Am Surg. 1999; 65: 972.

25. Ozlem N, Erdogan B. Repairing great duodenal defects in rabbits by PTFE patch. Acta Chir Belg. 1999; 99 (1): 17-21.

26. Astarcioglu H, Kocdor M. Sokmen S, Karademir S, Ozer E, Bora S. Comparison of different surgical repairs in the treatment of experimental duodenal injuries. Am J Surg. 2001; 181 (4): 309-12.

\section{Agradecimentos}

Sr. Álvaro Roberto Gonçalves Machado, Sr. Daniel Fiedler Funcionários do laboratório da Disciplina de Técnica Operatória e Cirurgia Experimental, PUCPR.

Dr. Indalécio Mainardes Sutil - Médico Veterinário, responsável pelo Biotério da PUCPR.

Sra. Rosana Nunes Ferreira Secretária da Disciplina de Técnica Operatória e Cirurgia Experimental, PUCPR.

\section{Correspondência}

Zacarias Alves de Souza Filho

Rua Padre Agostinho, 1923/1901

807100-000 Curitiba - PR

Te: (41)3336-3445

z.alves@pucpr.br
Conflito de interesse: nenhum Fonte de financiamento: nenhuma

Recebimento: 25/04/2005 Revisão: 23/05/2005

Aprovação: 22/06/2005

\section{Como citar este artigo:}

Souza Filho ZA, Greca FH, Rocha SL, Ioshii SO, Domanski NA, Kfouri D, Campos PDP, Silva RFKC. Enxerto de submucosa porcina no tratamento de lesões duodenais em cães. Acta Cir Bras. [periódico na Internet] 2005 Set-Out;20(5). Disponível em URL: $\underline{\text { htp://www.scielo.br }}$ 